\title{
Comparison of luminance distribution on the lighting surface of power LEDs
}

\author{
Dariusz Czyżewski, \\ Electrical Power Engineering Institute, Warsaw University of Technology, Koszykowa 75, 00-662 Warszawa,
}

Received December 16, 2019; accepted December 29, 2019; published December 31, 2019

\begin{abstract}
This work presents luminance distributions across the surface of mid- and high-power diodes. The changes in luminance on diode surfaces following changes in the observation angle were verified. Based on the conducted tests, non-uniform luminance distribution on LED surface for diverse observation angles (including the axial direction) was observed. Moreover, it was concluded that luminance changes are not in line with Lambert's law. As a result of research, it was also concluded that alterations of power-supply conditions do not exert any significant impact on the gradient of luminance changes on the surfaces of examined LEDs.
\end{abstract}

It is worth mentioning that light-emitting diodes can be classified as follows: low power - power up to $100 \mathrm{~mW}$, mid power - power up to $500 \mathrm{~mW}$, high power - typical power over $500 \mathrm{~mW}$ to a few or even a few dozen $\mathrm{W}$ (watts) and - ultra high power - multi-chip ones, usually COB LED - which power can exceed even as much as $300 \mathrm{~W}$.

Providing the right thermal conditions for diode operations and relatively low power and luminous flux from a single diode is the greatest challenge in the process of putting diodes to a variety of applications. [1-3]. In the interior design [4-5] this problem was solved by using low- and mid- power diodes. Luminaires of greater power and lower requirements, connected with dispersion of heat generated by LEDs, are obtained thanks to such a solution. However, in road lighting, a matrix of multiple high-power LEDs with high luminous efficiency and greater resistance to external factors was used (over 100 single LEDs) with high luminous efficiency and greater resistance to external factors [6]. But, in this case the heat from the luminaires has to be properly dispersed, which involves the need to use large radiators. This, in turn, influences the luminaire size and weight.

Regardless of application, the professional design of an optical system is of prime importance. In the optical system designing process, a designer has basic technical data provided by producers at his/her disposal. These basic technical data are described in more detail in literature on the subject [7], such as: color temperature or correlated color temperature [8], color rendering index,

\footnotetext{
*E-mail: dariusz.czyzewski@ien.pw.edu.pl
}

supply current, heat resistance [9], luminous flux, luminous intensity. However, luminance distribution on the light source surface is the parameter that is crucial yet fails to be presented in catalogue data. This parameter influences the choice of what light distribution solid is going to be like. Unfortunately, producers of lightemitting diodes do not provide this parameter in catalogues. Therefore, scientific research illustrating luminance distribution on LED surface is very important. Unfortunately, such research is rarely described in scientific literature [10-13].

The purpose of the conducted research was to establish luminance distribution on the surface of mid-and highpower LEDs, as well as to determine the influence of observation angle on luminance distribution.

A specially constructed measurement post was used in the tests. High-luminance light-emitting diodes were examined using a goniometer allowing measurements in (C, $\gamma$ ) system [14-18]. The diodes were accompanied by a special radiator that provided the right thermal stabilization of the examined diodes. A matrix luminance meter LMK98-3 Color (ILMD) and a specially selected lens were used for direct measurements. The LED operating temperature was controlled using a thermoelectric couple combined with a temperature meter. The light-emitting diodes were powered using a stabilized DC power supply. The electrical parameters were controlled using laboratory multimeters.

High-power light-emitting diodes, popular on the market, were selected for the tests. The products were both of the companies well or less known on the market. The most characteristic high-power diodes (LED1) and one mid-power ones (LED2) were selected for the tests. The basic diode parameters are presented in Table 1. At this stage of research, diodes that were not state-of-the-art were selected.

Table 1. Basic technical parameters of diodes subjected to research

\begin{tabular}{|l|c|c|}
\hline Technical parameter & $\begin{array}{c}\text { LED 1 } \\
\text { (high power) }\end{array}$ & $\begin{array}{c}\text { LED } 2 \\
\text { (mid power) }\end{array}$ \\
\hline $\begin{array}{l}\text { Luminous surface } \\
\text { dimensions }\end{array}$ & $2.1 \times 2.1 \times 1.2 \mathrm{~mm}$ & $2.05 \times 1.55 \times 0.25 \mathrm{~mm}$ \\
\hline Luminous flux (for $85^{\circ} \mathrm{C}$ ) & $2301 \mathrm{~m}$ & $301 \mathrm{~m}$ \\
\hline
\end{tabular}




\begin{tabular}{|l|c|c|}
\hline Power & $2.5 \mathrm{~W}$ & $0.2 \mathrm{~W}$ \\
\hline Supply current & $0.7 \mathrm{~A}$ & $0.065 \mathrm{~A}$ \\
\hline CRI & 82 & 85 \\
\hline CCTr & $6500 \mathrm{~K}$ & $4000 \mathrm{~K}$ \\
\hline $\begin{array}{l}\text { Maximum connector } \\
\text { temperature }\end{array}$ & $125^{\circ} \mathrm{C}$ & $125^{\circ} \mathrm{C}$ \\
\hline
\end{tabular}

The first stage of research was examining luminance distribution on the surface of light-emitting diodes. Figure 2 presents the examination results of luminance distribution from the axial direction $(\mathrm{C} 0, \gamma 0)$ for selected LEDs depicted in Fig. 1.

Measurement areas of various size expressed in percentage-terms (in respect to the total lighting surface) are presented in Fig. 1. Table 2 presents the results of tests of mean luminance and maximum luminance for the examined LEDs, for different measurement areas.
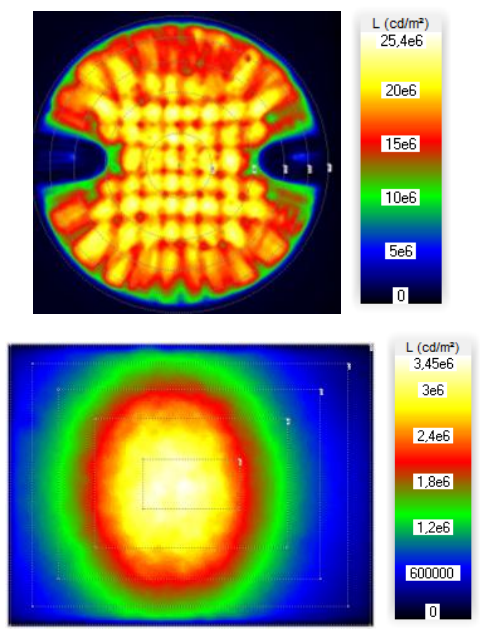

Fig. 1. Results of research on luminance distribution for the axial direction $(\mathrm{C} 0, \gamma 0)$ where the top photo presents LED 1 (high power), and the bottom - LED 2 (mid power).

Table 2. Results of tests of mean luminance and maximum luminance for the axial direction.

\begin{tabular}{|l|c|c|c|c|}
\hline \multirow{2}{*}{ Measurement area } & \multicolumn{2}{|c|}{ LED 1 (high power) } & \multicolumn{2}{c|}{ LED 2 (mid power) } \\
\cline { 2 - 5 } & $\begin{array}{c}\mathrm{L}_{\mathrm{av}} \\
{\left[\mathrm{Mcd} / \mathrm{m}^{2}\right]}\end{array}$ & $\begin{array}{c}\mathrm{L}_{\max } \\
{\left[\mathrm{Mcd} / \mathrm{m}^{2}\right]}\end{array}$ & $\begin{array}{c}\mathrm{L}_{\mathrm{av}} \\
{\left[\mathrm{Mcd} / \mathrm{m}^{2}\right]}\end{array}$ & $\begin{array}{c}\mathrm{L}_{\max } \\
{\left[\mathrm{Mcd} / \mathrm{m}^{2}\right]}\end{array}$ \\
\hline Area 1 (100\%) & 14,62 & 25,45 & 3.03 & 3.45 \\
\hline Area 2 (75\%) & 16,68 & 25,45 & 2.46 & 3.45 \\
\hline Area 3 (50\%) & 17,75 & 25,45 & 2.01 & 3.45 \\
\hline Area 4 (25\%) & 19,37 & 25,45 & 1.67 & 3.45 \\
\hline Area 5 (5\%) & 20,18 & 25,45 & 1.42 & 3.45 \\
\hline
\end{tabular}

The next stage of research was determining changes in luminance distribution for various observation angles. The results of the tests are presented in Figure 2 for LED 1 (high-power) and in Fig. 3 - for LED 2 (mid-power). Subsequent Figures present luminance distributions for $\mathrm{C} 0$ half-plane and gamma angles shifted from 0 to 75 degrees every 15 degrees.

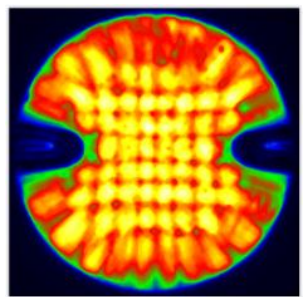

$\mathrm{C} 0 \gamma 0$

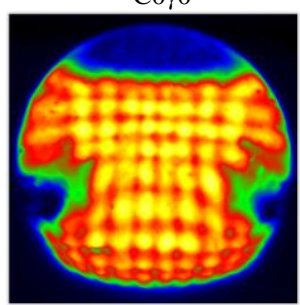

$\mathrm{C} 0 \gamma 30$

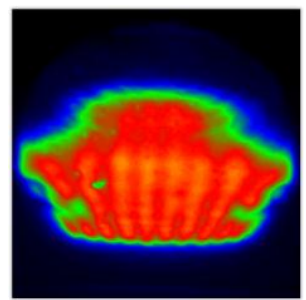

$\mathrm{C} 0 \gamma 60$

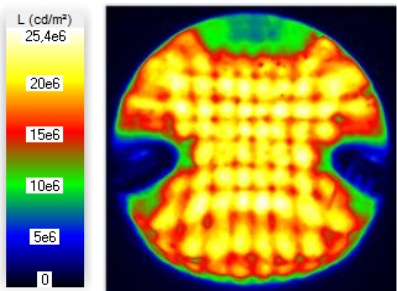

$\mathrm{C} 0 \gamma 15$
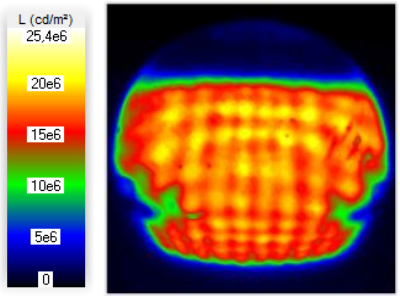

$\mathrm{C} 0 \gamma 45$
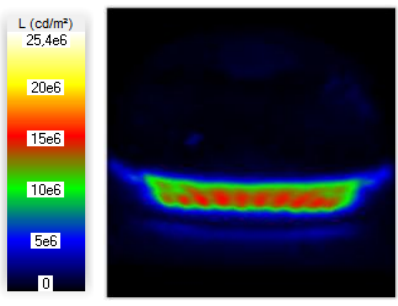

$\mathrm{C} 0 \gamma 75$

Fig. 2. Results of examination of luminance distribution for various axial directions $\left(\mathrm{C} 0, \gamma 0-\gamma 75\right.$ every $\left.15^{\circ}\right)$, for LED 1 (high-power).

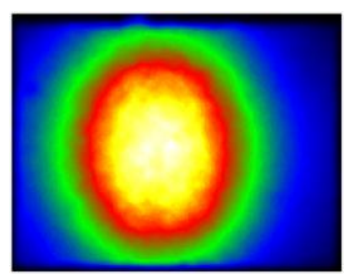

$\mathrm{C} 0 \gamma 0$

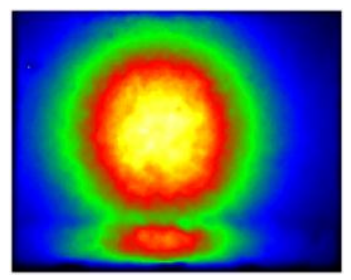

$\mathrm{C} 0 \gamma 30$

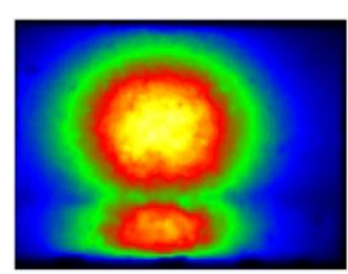

$\mathrm{C} 0 \gamma 60$

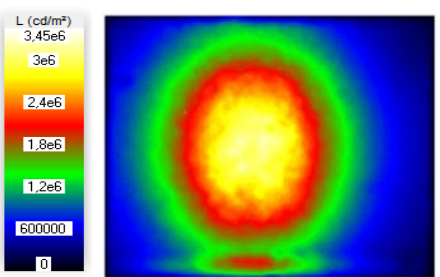

$\mathrm{C} 0 \gamma 15$

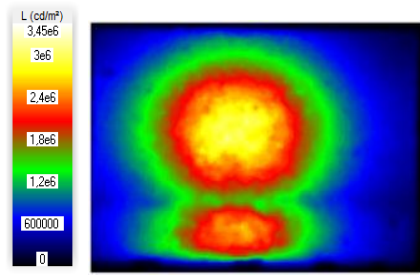

$\mathrm{C} 0 \gamma 45$
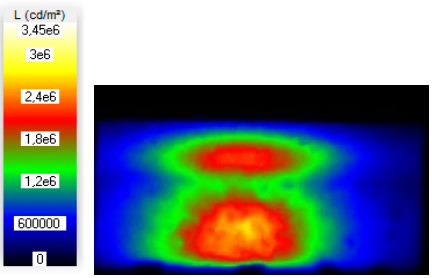

$\mathrm{C} 0 \gamma 75$

Fig. 3. Results of examination of luminance distribution for various axial directions $\left(\mathrm{C} 0, \gamma 0-\gamma 75\right.$ every $\left.15^{\circ}\right)$, for LED 1 (mid-power). 
The last stage of research was determining whether LED current supply changes influence the luminance distribution gradient. The results of this research were not presented in the work.

Analyzing the results of the conducted research regarding luminance distribution on the surface of the examined LEDs, it can be concluded that in all cases the distribution is not uniform. In order to illustrate luminance distribution better, measurement fields corresponding to $100 \%, 75 \%, 50 \%, 25 \%$ and $5 \%$ of the total lighting surface respectively were mapped onto it from the axial direction (as shown in Fig. 1).

Analyzing the results presented in Table 2, it was concluded that the maximum luminance is located in the smallest measurement field (5\% measurement field in the center of LED). In the case of LED 1 (high power), the maximum luminance was $24.45 \mathrm{Mcd} / \mathrm{m}^{2}$ and $74 \%$ higher than the mean luminance established for the entire lighting surface (area 1). In the case of LED 2 (mid power), however, the maximum luminance was $3.45 \mathrm{Mcd} / \mathrm{m}^{2}$ and $14 \%$ higher than the mean luminance established for the entire lighting surface (area 1). Therefore, it should be concluded that the luminance gradient for LED 2 (mid power) is considerably smaller (more uniform) than the luminance gradient on LED 1 (high power) surface. Moreover, it was observed that in the case of LED 2, the luminance distribution area is shifted to the left, away from the axis. The reason for this is placing a lighting micro-chip from the left side of the LED central axis (and not in the center), which contributed to the shifted luminance distribution image. Therefore luminance distribution is not symmetrical in the case of LED 2.

Analyzing the results of changes in luminance distribution in respect to the observation angle, it can be concluded that in the case of both light-emitting diodes, the distribution does not occur in line with Lambert's law. This is clear, in particular, in the case of gamma 90degree angles where the luminance equals 0 . In the case of LED 1, the maximum luminance for $\mathrm{C} 0 \gamma 90$ direction was $2.59 \mathrm{Mcd} / \mathrm{m} 2$, which is slightly over $10 \%$ of the maximum luminance values for the axial direction. In the case of LED 2, the maximum luminance for direction $\mathrm{C} 0 \gamma 90$ was $2.8 \mathrm{Mcd} / \mathrm{m} 2$, which was only $18 \%$ less than for the axial direction.

Hence the conclusion that also for diverse observation angles, LED 2 (mid power) has a far more uniform luminance distribution than LED 1 (high power).

Moreover, it was concluded that altering the power supply conditions does not affect the nature of luminance distribution on the surface of the examined LEDs.

Further works focus on selecting state-of-the-art diodes. It is expected that the maximum measured luminance will be very high and exceed the $100 \mathrm{mln} \mathrm{cd} / \mathrm{m}^{2}$ barrier.
The author would like to thank the Electrical Power Engineering Institute, Warsaw University of Technology for funding the possibility of publishing the research results.

\section{References}

[1] J. Fan, J. Cao, Ch. Yu, Ch. Qian, X. Fan, G. Zhang, Microelectronics reliability $\mathbf{8 4}, 140$ (2018). https://doi.org/10.1016/j.microrel.2018.03.033

[2] K. Bonislawski, I. Fryc, Przeglad Elektrotechniczny 88(3), 119 (2012).

[3] T. Kawabata, Y. Ohno, J. Modern Optics 60(14), 1176 (2013).

[4] P. Pracki, U. Blaszczak, IEEE Lighting Conference of the Visegrad Countries (Lumen V4) 2016.

[5] P. Tabaka, Przeglad Elektrotechniczny R. 91(5), 100 (2015). doi: 10.15199/48.2015.05.25

[6] D. Czyżewski, Przeglad Elektrotechniczny 86, 276 (2009).

[7] C.C. Miller; Y. Zong; Y. Ohno, Proc. SPIE 5530, 1117 (2004). https://doi.org/10.1117/12.566635

[8] D. Mozyrska Dorota; M. Wyrwas; I. Fryc, Przeglad Elektrotechniczny 88(4A), 232 (2012)

[9] K. Baran, A. Różowicz, H. Wachta, S. Różowicz, D. Mazur, Panel Sources, Energies 12, 3941 (2019). doi: 10.3390/en12203941

[10] D. Czyżewski, Crystals 9(12), 645 (2019). doi: 10.3390/cryst9120645

[11] L. Zheng, Z. Guo, W. Yan, Y. Lin, Y. Lu, H.C. Kuo, Z. Chen, L. Zhu, T. Wu, Y. Gao, IEEE Access 6, 51329 (2018). doi: 10.1109/ACCESS.2018.2869778

[12] S. Słomiński, Light Eng. 24, 45 (2016).

[13] I. Fryc, P. Jakubowski, K. Kołacz, Przeglad Elektrotechniczny 93(11), 186 (2017). doi: 10.15199/48.2017.11.38

[14] I. Fryc, Przeglad Elektrotechniczny 85(11), 317 (2009).

[15] I. Fryc, T. Dimitrova-Grekow, 2016 IEEE Lighting Conference of the Visegrad Countries (Lumen V4), 2016. doi: 10.1109/LUMENV.2016.7745523.

[16] CIE 235:2019, Optical measurement of led modules and light engines, ISBN 978-3-902842-25-1, doi: 10.25039/TR.235.2019.

[17] D. Czyżewski, Proc. of the 2016 IEEE Lighting Conference of the Visegrad Countries (Lumen V4), 2016. doi: 10.1109/LUMENV.2016.7745523.

[18] I. Rotscholl, K. Trampert, U. Krüger, F. Schmidt, Proc. SPIE 11144, 111440P (2019). doi: 10.1117/12.2531258 